\title{
Building State-Level Business Cycle Tracer Tools: Evidence from a Large Emerging Economy
}

\author{
Jéfferson A. Colombo ${ }^{1}$, Renan X. Cortes ${ }^{1}$, Fernando I. L. Cruz ${ }^{1,2}$ \& Luis H. Z. Paese ${ }^{1}$ \\ ${ }^{1}$ Economics and Statistics Foundation (FEE), Porto Alegre, Brazil \\ ${ }^{2}$ Ph.D. Candidate, Department of Economics, Federal University of Rio Grande do Sul (UFRGS), Brazil \\ Correspondence: Jéfferson A. Colombo, Rua Duque de Caxias, 1691 - Porto Alegre/RS, Zip code: 90010-283, \\ Brazil. Tel: 55-51-3216-9000. E-mail: jacolombo@ hotmail.com
}

Received: February 10, 2018

Accepted: March 9, 2018

Online Published: March 25, 2018

doi:10.5539/ijef.v10n5p14

URL: https://doi.org/10.5539/ijef.v10n5p14

\begin{abstract}
Tracing business cycle movements in a timely way can help government, firms, and consumers to allocate resources efficiently in the economy. However, analytical systems designed to monitor the business cycles are hard to find, especially in state-level economies and in emerging markets. In this paper, we present the methodology of construction of the Business Cycle Tracer of the State of Rio Grande do Sul - Brazil (BCT-RS), a tool that focuses on the visualization of a key subset of financial and socioeconomic data and allows users to analyze the interrelationships and the co-movements of those variables over time. Specifically, we discuss our methodological procedure to select leading, coincident and lagging indicators, including seasonal adjustment, cycle extraction, cross-correlation analysis and detection of turning points. We also describe the three functionalities of the BCT-RS -- time series, table of variations and macroeconomic dynamics. Overall, our proposed system offers a reliable representation of the current state of the business cycle before information about GDP becomes available. Importantly, our framework is generalizable to other states, especially in developing economies.
\end{abstract}

Keywords: local business cycles, business cycle tracer, developing economies, monitoring, data visualization

\section{Introduction}

Various institutions disseminate several economic indicators of subnational economies every month. Such information, which seeks to reflect the short-term fluctuations of the economy, is often volatile and can provide seemingly conflicting signals. Besides, users face costs of collecting and handling this scattered, unorganized information. The Business Cycle Tracer of Rio Grande do Sul - Brazil (Note 1) is a tool that systematizes these state-level financial and socioeconomic variables and, by focusing on the visualization of the data, allows users to analyze the interrelationships and the co-movements of the variables over time. Importantly, our tests and application are generalizable to other state economies, especially in developing markets, where data availability is scarce (similarly to our case).

Therefore, the purpose of this document is to present the methodology of the BCT-RS, emphasizing its functionalities and defining some fundamental concepts for its understanding. We also discuss the external validity of this tool -- the implementation of similar business cycle analytical systems in other subnational economies, for which these kind of applications are rare to find. Despite this gap, monitoring the state-level business cycle can help government, firms, and consumers to allocate resources efficiently in the economy. Hence, it is important to discuss and to spread knowledge about this kind of application.

Although the availability of state-level economic and financial data is limited for Brazilian states (Note 2), we collect information from several different institutions, such as the Economics and Statistics Foundation (FEE), the Brazilian Institute of Geography and Statistics (IBGE), the Federation of Industries of the State of Rio Grande do Sul (FIERGS), the Federation of Commerce of the State of Rio Grande do Sul (Fecomercio RS), the Central Bank of Brazil (Bacen), the Brazilian Department of Labor (MTE), the Alphaplan Surveys on Real Estate (Alphaplan), Economic Research Institute Foundation (FIPE), and ZAP Properties (ZAP Imóveis). We organize these multiple sources of data in five distinct dimensions -- economic activity, labor market, sentiment indicators, credit and delinquency rate, and price indexes. Together, this complementary group of indicators 
provides an overview of the economy being analyzed. In our case, all the information refers to the state of Rio Grande do Sul (RS), Brazil -- the 4th largest economy among the twenty-six states and one Federal District of Brazil (Brazilian Institute of Geography and Statistics, 2017).

The idea of providing a panorama has to be clear for users as it represents the core of the BCT-RS. Think of a doctor attending a patient. To assess his/her state of health, the doctor usually measures the blood pressure, performs routine exams, demands specific tests, etc. In the case of BCT-RS, the "patient" is the economy of Rio Grande do Sul, and we are observing it under five distinct aspects: output level, labor market, sentiment indicators, credit and delinquency rate, and price indexes. Just as no single medical examination is definitive, no single economic indicator is capable of diagnosing what is happening in the business cycle. Therefore, to monitor the economy, it is necessary to analyze a broad set of indicators, complementary to each other, in the same way as a physician evaluates multiple exams before diagnosing a patient.

In addition to describing the elaboration and use of the resources of the BCT-RS, this paper also briefly discusses issues related to business cycle analysis in subnational economies. Although these discussions usually apply to the reality of countries, the focus is on the peculiarities and precautions necessary to analyze state-level economies, whose productive matrix is often more concentrated, besides not having macroeconomic policy instruments such as the control of the money supply and exchange rate. Also, there are few studies concerning regional business cycles, and, to our knowledge, BCT-RS is the first tool to evaluate this information systematically in the Brazilian states. Therefore, FEE's experience in this area and the guidelines provided in this document can serve as a basis for other states to develop similar tools, which can support decision-making in public and private organizations.

Although scarce in most developing economies, analytical tools of business cycles can be observed in some developed countries. One is the Business Cycle Tracer (Note 3) (Van Ruth, Schouten, \& Wekker, 2005), developed and maintained by the Department of Business Cycle Statistics of the Statistics Netherlands, Dutch public institution equivalent to the Brazilian IBGE. The term tracer refers to the idea of "tracking" the movements of the economy, allowing a systematic and timing monitoring in frequency that leads to more accurately diagnose of the performance of the economy before the release of the Quarterly Gross Domestic Product (GDP). Another important tool to systematize a set of sparse information is the Eight different faces of the labor market, a tool made available by the Federal Reserve of New York (Note 4). From a set of indicators that synthesize the labor market into several "faces", such as level of employment, worked hours, labor demand, labor force participation and the match between supply and demand of workers and employers, it seeks to provide a complete diagnosis of that segment. Both systems share a common objective: to synthesize different socioeconomic information and to give the user a quick analysis, in a simple, interactive interface.

Given this international experience with the systematization of short-term data and information and its notorious benefits for analysts, researchers and other economic agents, we realized that there is this gap for state-level economies. The idea of creating the BCT-RS is focused on five main pillars:

- Objectivity;

- Focus on the visual aspect;

- Complementarity of the resources available in the tool;

- Representation of multiple dimensions of the local economy;

- Categorization of variables according to the usual timing concerning the local business cycle.

Together, these five principles guided the development process of the BCT-RS, which is summarized as follows. In section 2, we briefly discuss some theoretical aspects of different approaches to measuring economic cycles, as well as the statistical tests performed to categorize the variables regarding their timing in the economic cycle. In section 3, we present the methodological aspects regarding the procedures performed throughout the work -seasonal adjustment, cross-correlation analysis, cycle extraction, and turning points detection. The results of the categorization of variables are shown in section 4. In section 5, we detail the three features presented in the BCT-RS -- time series, table of variations and macroeconomic dynamics. We discuss the generalization of our framework to other state-level economies in section 6, and we draw our conclusions in section 7. Finally, we show the core results of the seasonal adjustment model adopted in this study in the Appendix A - Assessment of the Seasonal Adjustment Process.

\section{Brief Comments on the Measurement of Business Cycles}

Just as there is no consensus on the causes of business cycles, there is also no unanimity on how to measure them 
(Van Ruth et al., 2005). The National Bureau of Economic Research, a leading economic research institution in the United States, began systematic studies of the cycles in the US economy in the 1920s, publishing its first business cycles dating -- the name given to the chronology of economic expansions and recessions -- in 1929 (although the chronology in the United States extends up to 1854). In 1946 two of its researchers, Arthur Burns and Wesley Mitchell, published their most famous work, Measuring Business Cycles, containing the bases of the methodology now used by the NBER for the definition and measurement of business cycles, as well as the identification of recessive periods in the American economy. This approach has become known as the "classical approach to business cycles".

Using the classical approach, the NBER defines a recession as "a significant decline in economic activity spread across the economy, lasting more than a few months, normally visible in real GDP, real income, employment, industrial production, and wholesale-retail sales" (Note 5). This concept is important because it serves as a reference for the NBER Economic Cycle Dating Committee -- and equivalent institutions in other countries -- to differentiate economic recessions from small declines in the level of activity, which may occur even in times of economic expansions. Analogously, in periods of expansion, the level of economic activity increases substantially, in a generalized way, and this phase usually lasts a few years.

The classical approach, therefore, recommends that the cyclical phases (expansion and recession) should be identified from the analysis of the absolute level of economic activity. This implies that a recession, for example, should be associated with negative changes in the absolute level of economic activity. Some authors (e.g., Harding \& Pagan, 2002) defend the classical approach to date the business cycle because it would be the absolute variations in the level of economic activity that would, at the end of the day, be important to policymakers and the general public. Also, alternative methods of cyclical measurement would present as a disadvantage the high degree of complexity or poor definition of what is being evaluated. Finally, there is a conceptual question: should the focus be on analyzing the growth of an economy in absolute terms or relative to its potential growth? In economic theory, the objective is often to analyze the progress of an economy in the light of its potential development, which would be a negative aspect of using the classical approach. In subnational economies, however, the definition of "potential GDP" is not straightforward, which would reinforce the use of the classical approach to analyzing business cycles.

Thus, other definitions and, consequently, forms of measurement can be found in the literature. The "growth cycles approach" (growth cycles or deviation cycles), for instance, defines the business cycle of the product as deviations from a potential long-term trend. The cyclical component is therefore computed as fluctuations in the so-called output gap (Note 6). This approach received much attention especially in places where classic recessions (absolute falls in economic activity) were absent for long periods. It is the case, for example, in countries such as West Germany and Japan, which experienced high growth rates in the first decades after World War II (Zarnowitz, 1994). In the context of economic, social and political restructuring, the economic growth of these countries, rather than being interrupted by periods of contraction of the economy, oscillated between periods of greater or lesser growth, always positive.

The main disadvantage of the growth cycles approach is the arbitrary estimation of a long-term trend. Although there is a range of time series methods that serve this purpose -- such as a linear trend filter, structural decomposition of time series with Kalman filter, Hodrick-Prescott filter, Baxter-King filter, Christian-Fitzgerald filter, and so on -- the chosen method often imposes a particular interpretation on the cyclical phenomenon (Canova, 1998). Besides, it is not clear in the literature how these time series components -- trend and cycle -interact and influence each other (Zarnowitz \& Ozyildirim, 2006).

To circumvent such problems, some authors chose to try to identify cycles directly in the economic growth rates themselves, such as Friedman and Schwartz (1975), Mintz (1969), Chauvet (2002), among others. However, even indicators with well-defined cyclical patterns in the level series have irregular components that often dominate the characteristics of the growth rate series, especially in higher frequencies such as monthly or quarterly. An alternative to overcome the problem would be applying some filter to smooth the series, eliminating the erratic component (e.g., the use of moving averages). However, this procedure can distort the characteristics of the cyclical series, in particular regarding the timing of the turning points. Finally, it is worth mentioning that the cycle-threading timing in growth rates, in general, precedes that of the cycles in the level series.

Hence, there is no consensus as to which approach is best suited to measuring business cycles. The fact is that the specific characteristics of the analyzed economy should be a decisive factor for the analyst to define the most appropriate approach. In state-level applications, it is often more intuitive to follow the classical procedure. In 
this paper, we used both the classical and the growth cycles approaches to compare the results regarding the cyclical analysis (Note 7). For a more in-depth discussion of economic cycle measurement, we suggest reading Harding and Pagan (2002) and Artis et al. (2004).

\section{Methodological Aspects}

\subsection{Definition of the Reference Variable (Target)}

A crucial aspect in the diagnosis of how the variables of the system (variables present in the BCT-RS) behave relative to the local business cycle is to correctly define the target variable, that is, the variable that synthesizes the fluctuations of the local economy. Based on this "target" variable, we can categorize a given variable as leading, coincident, or lagging, depending on its movements compared to the local business cycle. For example, if cycles in the unemployment rate occur on average after the cycles in the level of economic activity, then the unemployment rate is considered a lagged variable (Note 8).

In general, the literature highlights GDP as the variable that individually best characterizes the cyclical movements of a given economy (National Bureau of Economic Research, 2008). However, the main disadvantage of this variable is that it is only observed in quarterly frequency; moreover, not all states have an available quarterly GDP estimate. Since the BCT-RS variables are released in monthly frequency, a monthly indicator capable of reproducing, even if imperfectly, the fluctuations of GDP would be strictly preferred.

As desirable properties of a good target variable, we highlight:

- To be highly correlated with the quarterly GDP of the economy being analyzed (quarterly reference variable). More than simple correlation, their peaks and troughs -- which mark the beginning of periods of recession and expansion, respectively -- should present similar pattern relative to the peaks and troughs of the quarterly GDP;

- $\quad$ To be released with a small lag relative to the period of competence (timing is a key factor for business cycle monitoring). For example, the data for Feb./2018 should be made available as close as possible to Feb./2018.

Considering the desirable characteristics for the reference variable (target), a potential monthly variable to represent the fluctuations of the RS economy is the Regional Economic Activity Indicator of the Central Bank of Brazil - IBCR-RS (Central Bank of Brazil, 2009). This indicator, published monthly by the Central Bank of Brazil, seeks to aggregate proxies of the agricultural, industrial and services sectors, using as weighting factors the value added from the Regional Accounts System (Note 9). Although it does not have the same coverage as the GDP, its movements appear to be adherent to the observed fluctuations in the level of regional economic activity (Braga et al., 2014). We perform empirical tests comparing the IBCR-RS with the quarterly GDP of Rio Grande do Sul during the available period (2002-2017), confirming that the IBCR-RS is a good proxy for the quarterly GDP of RS (see Figure 1).

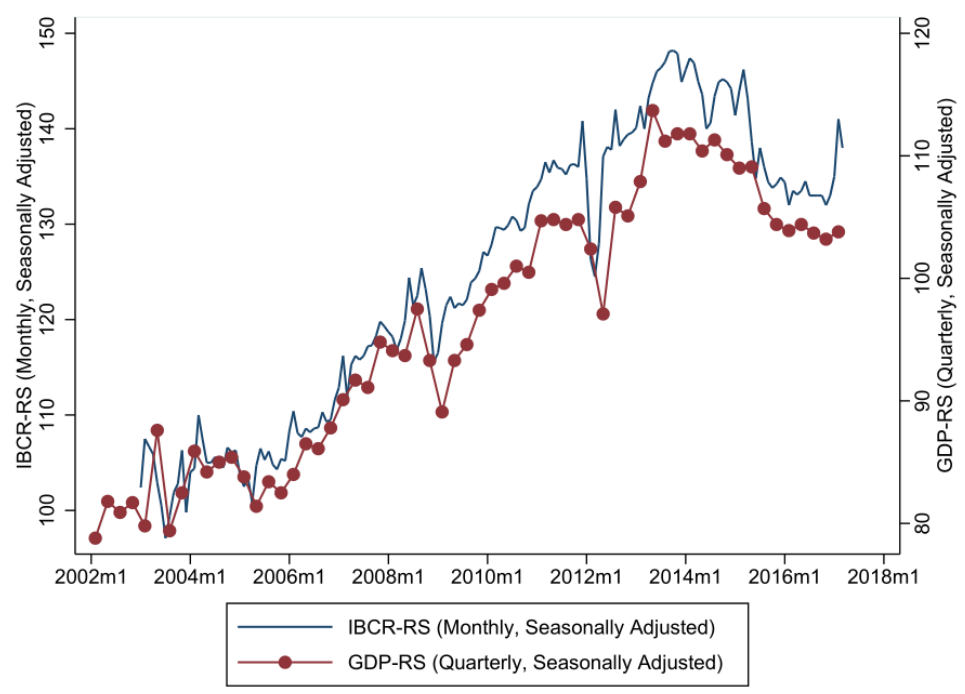

Figure 1.Volume index of the IBCR-RS and the quarterly GDP of the state of RS, $2003 \mathrm{~m} 1$ to $2017 \mathrm{~m} 3$ 
The coverage of the indicator, according to Central Bank of Brazil (2009), includes agriculture, forestry and logging activities; livestock and fisheries; manufacturing industry; trade and repair services; civil construction, housing and food services, and market health and education; and public administration, health, and education. Subsequent updates to the indicator were intended to bring its adherence even closer to the regional economic activity level variation reported in the System of Regional Accounts (Central Bank of Brazil, 2012).

\subsection{Seasonal Adjustment}

Seasonal adjustment is an important component in time series analysis. Seasonal patterns can be found in various economic series, such as agricultural production, retail sales, airline ticket sales, among many others. In general, these patterns are associated with specific events such as harvesting periods, year-end parties, school holidays, holidays, etc. When analyzing the behavior of these variables over time, especially when the objective is to capture cyclical patterns and long-term trends, it is necessary to remove the effect of these events, since the behavior of interest can be masked by them.

There are several programs that allow the analyst to isolate and remove the seasonal component from a time series, the most common of which are the X-12-ARIMA and X-13-ARIMA-SEATS developed in the US Census Bureau. The programs represent extensions of the X-11-ARIMA program of the Statistics Canada and the SEATS program of the Bank of Spain. Currently, IBGE and FEE use the X-13-ARIMA in the seasonal adjustment of the Quarterly Accounts.

For the reasons explained, we performed the seasonal adjustment of the variables in the BCT-RS using the seasonal package available for the $\mathrm{R}$ software (options we use include automatic ARIMA model search and outlier detection). Based on the procedures used by the IBGE for the seasonal adjustment of the Quarterly National Accounts, we adjusted the program specifications to the monthly frequency. Implicit procedures allow automatic identification of the model (additive or multiplicative), identification of worked days and Easter holiday effects in the estimation of the ARIMA model, automatically selecting the best alternative. For details, we suggest reading the U.S. Census Bureau (2017) program manual.

Regarding the BCT-RS specifically, we perform the seasonal adjustment tests using X-13-ARIMA-SEATS. The results of this application were then compared with the original series released by the data sources, when available (Note 10). With this comparison, it is possible to evaluate the quality of the seasonal adjustment we were performing. Results in "Appendix A - Assessment of the Seasonal Adjustment Process" show that our seasonally adjusted procedure nearly replicated the movement of seasonally adjusted series of IBGE and other available sources of data. For all the other series of the BCT-RS, where the sources of the research do not provide seasonally adjusted data, we provide an estimate of the variable free of the seasonal effects based on the application of the X-13-ARIMA-SEATS. In this case, the estimation of the seasonally adjusted variable is our estimates, based on the available raw data. This distinction is established in the description of the variables, within the Time Series feature, in the BCT-RS.

\subsection{Cross-Correlation Tests}

Cross-correlation tests help to identify possible leading, coincident, or lagging variables, as they provide the magnitude of the correlation between a time series in a given month $t$, and another in the same month $t$ or in another future month $(t+h)$ or past $(t-h)$. Formally, it is the correlation between $x_{t+h}$ and $y_{t}$, where $h=0, \pm 1, \pm 2, \ldots$. In this study we evaluated the correlation between the target variable (IBCR-RS) in a given month and all other variables of the BCT-RS in a window ranging from $\left(h_{\min }=-25\right.$ to 25$)$ months in the future $\left(h_{\max }=+25\right)$. Assuming that $h^{*}$ is the lag or lead where the maximum correlation occurs (in module), if $h^{*}<0$, the maximum correlation between the two variables occurs between $y_{t}$ and some past value of $x$-- in this case, $x$ is a candidate for leading; if $h^{*}>0, x$ is a candidate for lagging; finally, when $h^{*}=0, x$ and $y$ appear to be coincident (contemporaneous). In addition to the cross-correlation analysis, we also compare the peaks and troughs on the variables of the system with peaks and troughs in the target variable. For example, one should expect that peaks and troughs of leading (lagging) variables would occur, on average, before (after) peaks and troughs in the aggregate economy. For more information on cross-correlation tests in the context of business cycle indicators, see NYU Stern (2016).

\subsection{Double HP Filter}

We perform both cross-correlation and cyclical dating tests for the series expressed in levels and also for the cyclical component of the series. To obtain the growth cycle, we use the double HP filter as proposed by Gyomai and Guidetti (2008). This filter assumes that a series $\left(y_{t}\right)$ can be decomposed by the sum of one trend component $\left(b_{t}\right)$ and one of cycle, $\left(c_{t}\right)$, as follows: 


$$
y_{t}=b_{t}+c_{t}
$$

For $t=1,2, \ldots, T$. It is assumed that the component of the trend series $\left(b_{t}\right)$ varies smoothly over time with the measure of smoothness given by the sum of the square of its second difference. It is also assumed that the cycle $\left(c_{t}\right)$ understood as the deviations of $y_{t}$ around $b_{t}$, has an average close to zero over long periods. The filter allows us to obtain the sequence of linear functions, $b_{t}=\sum_{i=1}^{T} w_{i, t} y_{i}$, which solves the following programming problem:

$$
\min _{\boldsymbol{b}}\left\{\sum_{t=1}^{T}\left(y_{t}-b_{t}\right)^{2}+\lambda \sum_{t=1}^{T}\left[\left(b_{t}-b_{t-1}\right)-\left(b_{t-1}-b_{t-2}\right)\right]^{2}\right\}
$$

The fixed parameter $\lambda$ is chosen to penalize the variability in the growth series, thus controlling its smoothness. Despite this, the cycle obtained may still be noisy. To obtain a smoothed cycle, Gyomai and Guidetti (2008) propose the use of a double filtration, removing cycles greater than 120 months and less than 12 months. This is done using the values of $\lambda=133.107 .94$ and $\lambda=13.93$, respectively, in each of the filtrations (Gyomai \& Guidetti, 2008). In the former, the long-term trend is removed, while in the second, the noise is excluded. Finally, the extracted cycle is normalized. In this work the following normalization was used:

$$
c_{t}^{\prime}=100+\frac{c_{t}-\mu}{\sigma}
$$

Where $\mu$ is the mean and $\sigma$ the standard deviation of the series.

\subsection{Cyclical Dating: The Bry-Boschan Algorithm}

To detect the turning points in the variables, we use the Bry \& Boschan (1971) method applied to monthly data. The Bry-Boschan Algorithm is a way of mechanizing the dating procedure in the tradition followed by the National Bureau of Economic Research (NBER). Based on rules imposed on the behavior of the series, it is possible to classify peaks and troughs and, consequently, phases of expansions and recessions (Note 11). First, a window is chosen in order to identify maximums $\left(y_{t-k}, \ldots, y_{t-1}<y_{t}>y_{t+1}, \ldots, y_{t+k}\right)$ and local minimums $\left(y_{t-k}, \ldots, y_{t-1}>y_{t}<y_{t+1}, \ldots, y_{t+k}\right)$. Next, a minimum period is required for the duration of a phase of the cycle, i.e. the time elapsed between a peak (trough) and a trough (peak). Using the Bry and Boschan (1971) approach, we also impose a minimum duration for the complete cycle, from peak to peak or trough to trough. These restrictions aim to purge swings and noises not related to the business cycle. The suggested parameters for monthly data are (Bry \& Boschan, 1971):

$$
\text { Considered parameters }=\left\{\begin{array}{l}
\text { Window: Equal to } 5 \text { months }(k=5) \\
\text { Minimal phase: Greater than or equal to } 5 \text { months } \\
\text { Minimal cycle: Greater than or equal to } 15 \text { months }
\end{array}\right.
$$

Additionally, we impose a restriction of magnitude so that falls very severe, although rapid, are classified as recessions (Note 12). Finally, it is noteworthy that in these specifications, the algorithm does not capture cycles at very low frequencies, such as decennial or secular.

It is noteworthy that after dating the series, all identified economic downturns and upwards in the indicators were criticized by the authors. In this process, we evaluated the behavior of the series in the light of the recessions in the Brazilian economy (dated by the Brazilian Committee of Dating Cycles -- CODACE) and cyclical movements observed in the Brazilian GDP (IBGE). Finally, we also used industry-level information on the value added of the state of Rio Grande do Sul.

\section{Results of the Stratification Procedure: Leading, Coincident or Lagging Indicators}

Using the methods described in section 3, we obtained the categorization of variables concerning the timing of their turning points in the economy: leading, coincident or lagging. The result of the cross-correlation tests in the series expressed in level, first difference and cyclical component extracted by the double HP filter are shown in Table 1 . 
Table 1. Summary of the tests to categorize each variable of the BCT-RS according to its cyclical behavior: leading, coincident or lagging

\begin{tabular}{|c|c|c|c|c|c|c|}
\hline \multirow[b]{2}{*}{ Label } & \multicolumn{3}{|c|}{ A) Level } & \multicolumn{3}{|c|}{ B) 1st Difference } \\
\hline & $\begin{array}{l}\text { Opt. lag } \\
\text { (xcorr) }\end{array}$ & $\begin{array}{l}\text { Max. Corr. } \\
\text { Coeff. }\end{array}$ & Category & $\begin{array}{l}\text { Opt. lag } \\
\text { (xcorr) }\end{array}$ & $\begin{array}{l}\text { Max. Corr. } \\
\text { Coeff. }\end{array}$ & Category \\
\hline Industry - Confidence (FIERGS) & 12 & $-0,65$ & $\mathrm{~N}$ & -11 & 0.19 & $\mathrm{~L}$ \\
\hline Intention of Household Consumption (ICF - FECOMERCIO/RS) & 24 & -0.71 & $\mathrm{~N}$ & -2 & 0.33 & $\mathrm{~L}$ \\
\hline Real Estate - Expectations (IEMI/ALPHAPLAN) & -12 & 0.57 & $\mathrm{~L}$ & - & - & $\mathrm{L}$ \\
\hline Industry - Production (PIM/IBGE) & 24 & -0.35 & $\mathrm{~N}$ & 0 & 0.39 & $\mathrm{C}$ \\
\hline Retail Sales (PMC/IBGE) & 0 & 0.96 & $\mathrm{C}$ & 0 & 0.22 & $\mathrm{C}$ \\
\hline IBCR-RS (Central Bank of Brazil) & 0 & 1.00 & $\mathrm{C}$ & 0 & 0.70 & $\mathrm{C}$ \\
\hline Real Income (PED/FEE) & -2 & 0.91 & $\mathrm{C}$ & -1 & 0.26 & $\mathrm{C}$ \\
\hline Industry - CU (\%) (FIERGS) & 21 & -0.55 & $\mathrm{~N}$ & 1 & 0.18 & $\mathrm{C}$ \\
\hline Industry - Purchases (FIERGS) & 18 & -0.54 & $\mathrm{~N}$ & 0 & 0.29 & $\mathrm{C}$ \\
\hline Industry - Performance (FIERGS) & 22 & -0.44 & $\mathrm{~N}$ & 0 & 0.38 & $\mathrm{C}$ \\
\hline Employment - Agribusiness (FEE) & 0 & 0.95 & $\mathrm{C}$ & 0 & 0.26 & $\mathrm{C}$ \\
\hline Services (PMS/IBGE) & 3 & 0.72 & LA & 5 & 0.13 & LA \\
\hline Unemployment Rate (\%) (PED/FEE) & 0 & -0.96 & $\mathrm{C}$ & 0 & 0.29 & $\mathrm{C}$ \\
\hline Duration of Unemployment (months) (PED/FEE) & -4 & -0.90 & $\mathrm{~L}$ & 4 & -0.32 & LA \\
\hline Credit (R\$ Millions, Central Bank of Brazil) & 0 & 0.96 & $\mathrm{C}$ & 5 & 0.33 & LA \\
\hline Delinquency Rate (\%) (Central Bank of Brazil) & -10 & 0.34 & $\mathrm{~N}$ & 2 & 0.26 & $\mathrm{C}$ \\
\hline $\begin{array}{l}\text { Sales Tax - Deflated (CPI) (State Department of Taxation and } \\
\text { Finance) }\end{array}$ & 0 & 0.91 & $\mathrm{C}$ & -3 & 0.10 & $\mathrm{~N}$ \\
\hline Exports - Volume Index - RS (FEE) & 24 & 0.43 & $\mathrm{~N}$ & 20 & -0.15 & $\mathrm{~N}$ \\
\hline $\begin{array}{l}\text { Ratio between hiring and separation wages (Brazilian Department } \\
\text { of Labor) }\end{array}$ & -8 & 0.48 & $\mathrm{~L}$ & 1 & 0.12 & $\mathrm{~N}$ \\
\hline \multirow[t]{2}{*}{ Return on Exports - RS (FEE) } & 20 & 0.54 & $\mathrm{~N}$ & 20 & 0.19 & $\mathrm{~N}$ \\
\hline & \multicolumn{3}{|c|}{ C) Double HP Filter } & \multicolumn{3}{|c|}{ D) Averages and Assessment } \\
\hline Label & $\begin{array}{l}\text { Opt. lag } \\
\text { (xcorr) }\end{array}$ & $\begin{array}{l}\text { Max. Corr. } \\
\text { Coeff. }\end{array}$ & Category & $\begin{array}{c}\text { Average } \\
\text { lag } \\
\text { (xcorr) }\end{array}$ & $\begin{array}{c}\text { Average } \\
\text { Corr. } \\
\text { Coeff. }\end{array}$ & Category \\
\hline Industry - Confidence (FIERGS) & 12 & $-0,68$ & LA & 4 & $-0,38$ & $\mathrm{~L}$ \\
\hline Intention of Household Consumption (ICF - FECOMERCIO/RS) & -2 & 0,84 & $\mathrm{~L}$ & 7 & 0,15 & $\mathrm{~L}$ \\
\hline Real Estate - Expectations (IEMI/ALPHAPLAN) & -11 & 0.48 & $\mathrm{~L}$ & -11 & 0.52 & $\mathrm{~L}$ \\
\hline Industry - Production (PIM/IBGE) & -1 & 0.79 & $\mathrm{C}$ & 8 & 0.27 & $\mathrm{C}$ \\
\hline Retail Sales (PMC/IBGE) & 0 & 0.84 & $\mathrm{C}$ & 0 & 0.67 & $\mathrm{C}$ \\
\hline IBCR-RS (Central Bank of Brazil) & 0 & 1.00 & $\mathrm{C}$ & 0 & 0.90 & $\mathrm{C}$ \\
\hline Real Income (PED/FEE) & 3 & 0.70 & LA & 0 & 0.62 & $\mathrm{C}$ \\
\hline Industry - CU (\%) (FIERGS) & -1 & 0.47 & $\mathrm{C}$ & 7 & 0.04 & $\mathrm{C}$ \\
\hline Industry - Purchases (FIERGS) & 0 & 0.63 & $\mathrm{C}$ & 6 & 0.13 & $\mathrm{C}$ \\
\hline Industry - Performance (FIERGS) & 1 & 0.70 & $\mathrm{C}$ & 8 & 0.21 & $\mathrm{C}$ \\
\hline Employment - Agribusiness (FEE) & 3 & 0.75 & LA & 1 & 0.65 & $\mathrm{C}$ \\
\hline Services (PMS/IBGE) & 6 & 0.82 & LA & 5 & 0.56 & LA \\
\hline Unemployment Rate (\%) (PED/FEE) & 2 & -0.67 & $\mathrm{C}$ & 1 & -0.45 & LA \\
\hline Duration of Unemployment (months) (PED/FEE) & 6 & -0.59 & LA & 2 & -0.60 & LA \\
\hline Credit (R\$ Millions, Central Bank of Brazil) & 6 & 0.75 & LA & 4 & 0.68 & LA \\
\hline Delinquency Rate (\%) (Central Bank of Brazil) & 5 & 0.64 & LA & -1 & 0.41 & LA \\
\hline $\begin{array}{l}\text { Sales Tax - Deflated (CPI) (State Department of Taxation and } \\
\text { Finance) }\end{array}$ & -2 & 0.28 & $\mathrm{~N}$ & -2 & 0.43 & $\mathrm{~N}$ \\
\hline Exports - Volume Index - RS (FEE) & 17 & -0.35 & $\mathrm{~N}$ & 20 & -0.02 & $\mathrm{~N}$ \\
\hline $\begin{array}{l}\text { Ratio between hiring and separation wages (Brazilian Department } \\
\text { of Labor) }\end{array}$ & -1 & 0.52 & $\mathrm{C}$ & -3 & 0.37 & $\mathrm{~N}$ \\
\hline Return on Exports - RS (FEE) & 10 & 0.40 & LA & 17 & 0.38 & $\mathrm{~N}$ \\
\hline
\end{tabular}

Note. $\mathrm{L}=$ Leading; $\mathrm{C}$ = Coincident; LA = Lagging; $\mathrm{N}=$ None (Unclassified). Besides the cross-correlation results, overall assessment (Panel D) also considers the turning points of each variable relative to the turning points in the target variable - results shown in Table 2 and Table 3.

Source: authors' elaboration. 
In the cross-correlation analysis for different ways of measuring the series (level differences or first cyclical component), the Bry-Boschan algorithm was used to identify phases of expansion and recession in the system variables. The result of this application is outlined in Table 2. From these peaks and troughs -- which signalize the beginning of a recessive and an expansionary phase of the economic cycle, respectively --, it is possible to calculate the average difference (in months) between these points of cyclical reversal in the reference indicator (IBCR-RS) and each variable in the system.

Table 2. Result of the dating procedure on individual variables - peaks and troughs identified by the Bry-Boschan algorithm

\begin{tabular}{|c|c|c|c|c|c|c|c|}
\hline $\begin{array}{l}\text { Name / Turning points in the target } \\
\text { variable (IBCR-RS) }\end{array}$ & $\begin{array}{l}\text { Jan-05 } \\
\text { Trough } \\
\end{array}$ & $\begin{array}{c}\text { Sep-08 } \\
\text { Peak }\end{array}$ & $\begin{array}{l}\text { Jan-09 } \\
\text { Trough } \\
\end{array}$ & $\begin{array}{l}\text { Nov-11 } \\
\text { Peak }\end{array}$ & $\begin{array}{l}\text { Mar-12 } \\
\text { Trough } \\
\end{array}$ & $\begin{array}{c}\text { Sep-13 } \\
\text { Peak }\end{array}$ & $\begin{array}{l}\text { Oct-16 } \\
\text { Trough } \\
\end{array}$ \\
\hline Industry - Production & Apr-06 & Sep-08 & Dec-08 & Dec-11 & Feb-12 & Feb-14 & - \\
\hline Retail Sales & Sep-05 & Jun-08 & - & - & Oct-11 & Feb-14 & - \\
\hline Services & - & - & - & - & - & Apr-14 & - \\
\hline Unemployment Rate (\%) & Mar-06 & Dec-08 & Apr-09 & - & - & Aug-14 & - \\
\hline Duration of Unemployment (months) & Nov-06 & Mar-09 & Apr-09 & Feb-13 & Jul-13 & Oct-14 & - \\
\hline Real Income & Aug-06 & - & - & Jan-11 & Feb-12 & Jan-14 & - \\
\hline Industry - Confidence & - & - & - & - & - & Nov-12 & Mar-15 \\
\hline Industry - CU (\%) & Jul-05 & Sep-08 & May-09 & Apr-11 & May-12 & May-13 & Aug-16 \\
\hline Industry - Purchases & Nov-05 & Jun-08 & Jan-09 & Jun-10 & Feb-12 & Mar-13 & - \\
\hline Industry - Performance & Mar-06 & Sep-08 & Mar-09 & May-11 & Jun-12 & Oct-13 & Oct-16 \\
\hline Intention of Household Consumption & - & - & - & Dec-10 & Jan-12 & Apr-13 & Aug-16 \\
\hline Credit (R\$ Millions) & - & - & - & Jun-12 & Sep-12 & Jan-15 & Jan-17 \\
\hline Delinquency Rate (\%) & - & Dec-08 & Aug-09 & May-11 & Apr-12 & Feb-14 & Mar-16 \\
\hline Real Estate - Expectations & - & - & - & - & - & - & - \\
\hline Employment - Agribusiness & - & Jul-08 & May-09 & Dec-11 & Mar-12 & Aug-14 & Jul-16 \\
\hline
\end{tabular}

Source: authors' elaboration.

Intuitively, the leading variables will show turning points, on average, before the reference variable (negative difference in months); in turn, the coincident indicators will present turning points that, on average, match the economic cycle; finally, the lagging variables will show cyclical reversion, on average, after the turning points of the reference variable (positive difference in months). This information and the summary of the classification variables can be seen in Table 3 .

Table 3. Average difference (in months) between peaks and troughs in the target variable (IBCR-RS) and the other variables of the system

\begin{tabular}{|c|c|c|c|c|c|c|c|c|c|}
\hline $\begin{array}{l}\text { Name / Turning points in the target } \\
\text { variable (IBCR-RS) }\end{array}$ & $\begin{array}{l}\text { Jan-05 } \\
\text { Trough }\end{array}$ & $\begin{array}{l}\text { Sep-08 } \\
\text { Peak }\end{array}$ & $\begin{array}{l}\text { Jan-09 } \\
\text { Trough }\end{array}$ & $\begin{array}{c}\text { Nov-11 } \\
\text { Peak }\end{array}$ & $\begin{array}{l}\text { Mar-12 } \\
\text { Trough }\end{array}$ & $\begin{array}{c}\text { Sep-13 } \\
\text { Peak }\end{array}$ & $\begin{array}{l}\text { Oct-16 } \\
\text { Trough }\end{array}$ & $\begin{array}{l}\text { Average Lead/ } \\
\text { Lag (months) }\end{array}$ & $\begin{array}{c}\text { Final } \\
\text { Categoriza-tion }\end{array}$ \\
\hline Industry - Production & 3 & 0 & -1 & 1 & -1 & 5 & - & 0 & Coincident \\
\hline Retail Sales & -4 & -3 & - & - & -5 & 5 & - & -2 & Coincident \\
\hline Services & - & - & - & - & - & 7 & - & 7 & Lagging \\
\hline Unemployment Rate (\%) & 2 & 3 & 3 & - & - & 11 & - & 5 & Lagging \\
\hline Duration of Unemployment (months) & 10 & 6 & 3 & 15 & 16 & 13 & - & 10 & Lagging \\
\hline Real Income & 7 & - & - & -10 & -1 & 4 & - & 2 & Coincident \\
\hline Industry - Confidence & - & - & - & - & - & -10 & -19 & -10 & Leading \\
\hline Industry - CU (\%) & -6 & 0 & 4 & -7 & 2 & -4 & -2 & -3 & Coincident \\
\hline Industry - Purchases & -2 & -3 & 0 & -17 & -1 & -6 & - & -5 & Leading \\
\hline Industry - Performance & 2 & 0 & 2 & -6 & 3 & 1 & 0 & -1 & Coincident \\
\hline Intention of Household Consumption & - & - & - & -11 & -2 & -5 & -2 & -5 & Leading \\
\hline Credit (R\$ Millions) & - & - & - & 7 & 6 & 16 & 3 & 8 & Lagging \\
\hline Delinquency Rate (\%) & - & 3 & 7 & -6 & 1 & 5 & -7 & 1 & Coincident \\
\hline Real Estate - Expectations & - & - & - & - & - & - & - & - & Leading \\
\hline Employment - Agribusiness & - & -2 & 4 & 1 & 0 & 11 & -3 & 2 & Coincident \\
\hline
\end{tabular}

Source: authors' elaboration. 
The analysis of cyclical dating here is more important than the cross-correlation because it provides evidence of the transition of the variables from one phase to another of the cycle, something that simple correlation does not capture. To categorize variables according to the timing of their movements vis-a-vis the movements of the regional economy, it is important to focus on the transition dates between one phase and another, which are given in Table 3.

Although in some cases the results indicate a consistent relation of leads and lags, in some indicators this relationship is not consistent, and is often susceptible to the way in which the variable is measured (if level, first difference, or cyclical component). In addition, many series have a very short history, which makes it difficult to perform and interpret tests. For ambiguous cases, we use evidence from the literature to classify the variable as leading, coincident or lagging. Comparisons between the classification suggested by our tests and the categorization found in the literature are important to ratify the classification of some variables, such as the unemployment rate (\%) (Note 13). The fluctuations over time of the variables classified as leading, coincident and lagging can be observed in Figure 2.

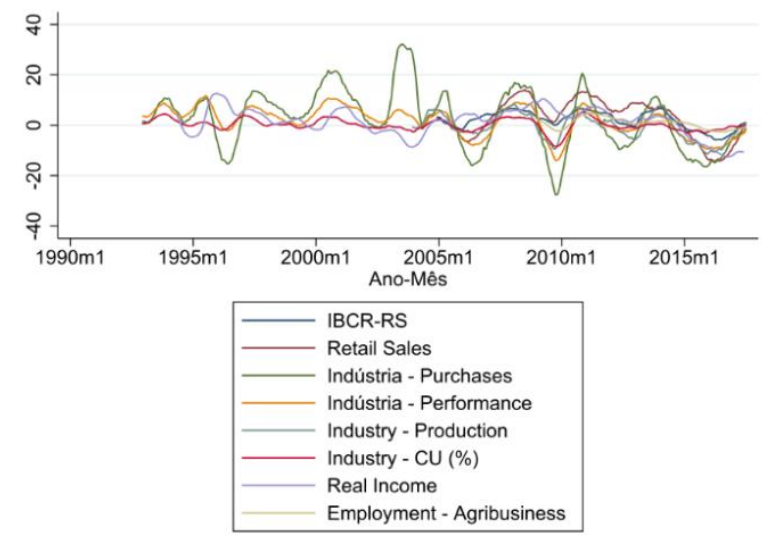

(a) Group 1: coincident variables

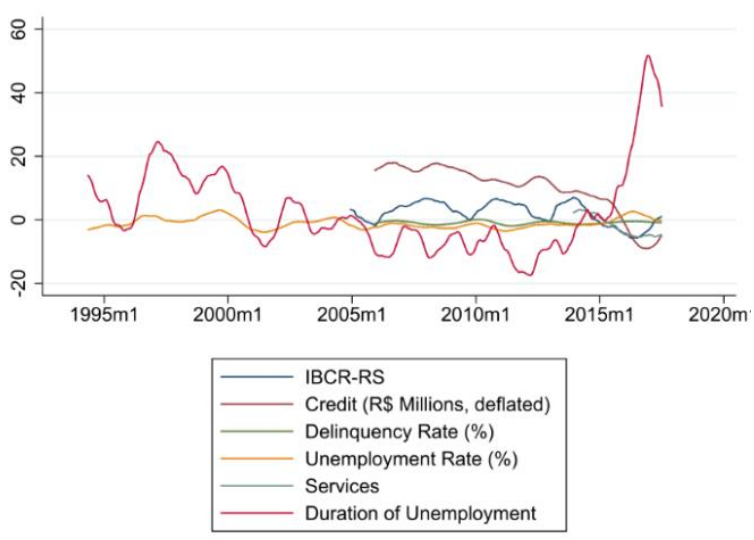

(b) Group 2: lagging variables

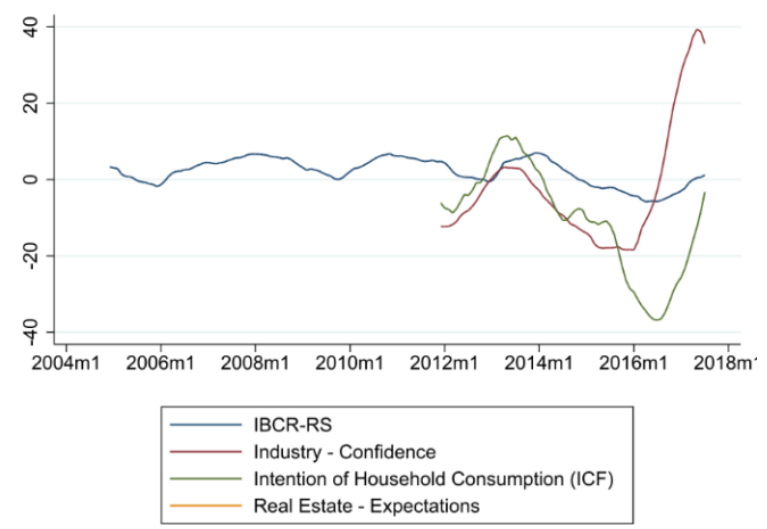

(c) Group 3: leading variables

Figure 2. Cumulative 12 months growth rate of the variables categorized as leading, coincident or lagging

Note. In each of the subfigures, we include the IBCR-RS (Central Bank of Brazil) as a reference indicator (target), as it was the variable used as a proxy to the activity level of the state's economy. The classification of the categories variables leading, coincident and lagging take into account fluctuations in all variables of the BCT-RS relative to the reference variable (IBCR-RS).

Source: authors' elaboration.

One should also note that the categorization according to the timing is only used in BCT-RS at the feature called Macroeconomic Dynamics, where co-movements of these different variables can be observed in detail. It is important to note that observing these co-movements in macroeconomic variables is a key factor to understand business cycle fluctuations (Chauvet, 1998). More information on using this feature of BCT-RS is exposed in the subsection Macroeconomic Dynamics. 


\section{Components of the Business Cycle Tracer of Rio Grande do Sul (BCT-RS)}

\subsection{Presentation}

When one opens the website <visualiza.fee.tche.br/bct-rs> (retrieved January 10, 2018), he or she is directed to the tab "Presentation". It contains the essential information about the BCT-RS and a summary of its features (application characteristics). There is also information about the institution responsible for the application creation (FEE), a tutorial (video) and e-mail to contact in case of questions.

\subsection{Time Series}

In "Time Series", the user can refer to several indicators through a time series graphic. The indicators are grouped into five dimensions of the state's economy:

1) Economic Activity: composed of indicators for the cyclical monitoring of the activity level of the state's economy. It includes proxies of manufacturing industry -- such as physical production, Capacity utilization (CU), purchases, etc. --, trade, services and the general activity level (IBCR-RS).

2) Labor Market: represented by variables that indicate the cyclical trends in the labor market. Several sources of series are included (Employment and Unemployment Survey - PED - and General Register of Employment and Unemployment - CAGED / RAIS) to differentiate indicators on the metropolitan area of Porto Alegre (PED) and the whole state (CAGED), as well as the formal and informal aspect of the occupation. These indicators include the unemployment rate, the average time spent in a job search, the mass of real income, the level of formal employment in agribusiness and the total formal employment in the overall economy.

3) Sentiment Indicators: integrated by indicators of perception, representing different segments of the economy: industry (from FIERGS), real estate (from Alphaplan Intelligence Research in partnership with the Sinduscon-RS), and trade (Intent of Household Consumption from Fecomercio-RS). This dimension seeks to capture the feeling of economic agents regarding the present situation and also their expectations for the following months.

4) Credit and Delinquency Rate: made up of delinquency rate and credit indicators (credit portfolio balance in RS), and represents the sum of the balance of individuals and corporations. Data is obtained from the Credit Information System (SCR) of the Brazilian Central Bank for the state of Rio Grande do Sul and reflect the present value of loans recorded in the final month (Central Bank of Brazil, 2017). This database contains information on debtors of an amount greater than $\mathrm{R} \backslash \$ 1,000.00$. The regional distribution of the data is based on the fiscal address of borrowers.

5) Price Indexes: consists of variables measuring the price change in different sectors of the state economy. For example, this group contains information about the Consumer Price Index (CPI) for the metropolitan area of Porto Alegre, the capital of the state of Rio Grande do Sul (overall index and its main results). It is also exposed in this group of variables information on the prices of residential and commercial properties in Porto Alegre, both announced prices of sale or lease.

The purpose of classification these dimensions is to facilitate the organization of information, arranging them in a logical sequence so that the user can make inference on how the state economy is behaving in multiple aspects. The choice of indicators within each of these categories (i.e., dimensions) aimed to give the user a broad picture of that dimension, by analyzing variables that are complementary rather than substitutes.

\subsection{Table of Variations}

The Table of Variations is a feature that aims to complement the analysis of the previous feature, "Time Series". While the purpose of that feature is the quick and orderly graphical inspection of variables, the purpose of this tool is to observe both the level of the series as their rates of change in a given period (month-year).

\subsubsection{Growth Rates}

To provide an accurate picture of the state economy, we calculate the growth rates in four different ways: month against the same month of the previous year, cumulated twelve months, month against the previous month, and moving average of three months. The manner of calculating the rate of change is explained below.

\section{1) Not seasonally adjusted data}

- Month over the same month of the previous year (t/t-12): refers to the monthly change considering the same period last year, so free of seasonal influences (Note 14).

- Accumulated twelve months ([t, .., $\mathrm{t}-11] /[\mathrm{t}-12, \ldots, \mathrm{t}-23])$ : refers to the cumulative change in a twelve 
months moving-average window.

\section{2) Seasonally adjusted data}

- Month against the previous month ( $\mathrm{t} / \mathrm{t}-1)$ : is the monthly variation of the series relative to the previous month, considering seasonal factors.

- Three-months moving average variation ([t, ..., $\mathrm{t}-3] /[\mathrm{t}-1 \quad \ldots \mathrm{t}-4])$ is the cumulative change in a three-month moving average window, whereas the denominator is the immediately preceding three months period.

\subsubsection{Colors and Signs of Variations}

The purpose of these various forms of variation computation is to make the table as informative as possible. In addition, two aspects are considered to show the information in the table:

- Symbol: The first aspect is the representation of an arrow indicating the direction signal. For positive variations, the arrow points upwards; for negative variations, downwards.

- Color: The information contained in the colors is different from that contained in the arrows (symbols). Colors express the quality idea of variation: green signals improvement; red, worsening. It is important that this point is made clear to the user because the symbols and colors can give conflicting information at first glance, but in fact, they are not. For example: for countercyclical series (Note 15) (those that move contrary to cycle of the economy of Rio Grande do Sul), such as unemployment rate and average time of job search, positive variations will be indicated with the up arrow, however the color will be red, since these variations indicate a worsening in the labor market dimension. In the case of pro-cyclical variables, positive variations are accompanied by green. Therefore, the interpretation based on colors focuses on the qualitative aspect of the variations, while the arrow indicates if the series varied positively or negatively. The informational content of the color is particularly important in view of the possibility of giving action to the table: as time goes by and information is being updated, the overall color of the table indicates the occurrence of expansion periods (mostly green table) and contraction (mostly red table), which is a kind of diffusion indicator (Note 16).

\subsection{Macroeconomic Dynamics}

The Macroeconomic Dynamics is a feature of the BCT-RS inspired on the Dutch Business Cycle Tracer (Van Rutg et al., 2005). It was designed to achieve three objectives:

- Assist in the analysis of the short-term fluctuations of the economy of Rio Grande do Sul: The focus on the visual aspect allows a quick understanding of the behavior of important and complementary economic variables at a given point in time (cross-section). For example, how did the cyclical variables of RS behave in July 2017? The monitor makes a comparative analysis of indicators -- including GDP, which acts as a reference for other system variables -- easier to visualize, compare and interpret.

- Allow visualization of the dynamics of key indicator fluctuations over time: With the functionality of macroeconomic dynamics, the user can observe the co-movements of system variables over time. This analysis is particularly important if it is performed separately in periods of contraction and expansion of the economic activity of the state of Rio Grande do Sul, where factors such as the degree of diffusion and the asymmetry of these movements can be analyzed. Possible heterogeneities in variables representing different dimensions of the local economy - including regional aspects - can be easily identified too.

- Filtering variables according to the time profile relative to the local business cycle: allows the user to analyze the movements of variables categorized according to their timing relative to the local business cycle: leading, coincident and lagging variables. Therefore, the monitor also helps in the prognosis of the economy (focus on the leading variables), as well as in the current situation (coincident variables) and in the confirmatory movements (lagging variables).

From a slightly more formal perspective, the monitor allows visualization of system variables in four different quadrants. Let $i=1, \ldots, n$ be the variable $i$ and $t=1, \ldots, m$ the time period $t, y$-axis represents the accumulated growth in 12 months $(\%)$ of the $i$-th series in the $t-t h$ period; the $\mathrm{x}$-axis represents the acceleration, i.e., the absolute variation of the growth rate (Note 17). Thus, indicators with a positive (negative) rate of change in the last 12 months, considering the period (month/year) will be above (below) the origin. In other words, if the series presents a positive variation accumulated in 12 months, it will be in the 1st or 2nd quadrants; if there is a negative accumulated variation, it will be in the 3rd or 4th quadrants. Concerning the second aspect considered by the monitor (acceleration), the indicators that show acceleration (deceleration) in 
the growth rate will be to the right (left) of the origin. Put another way, in the 1st or 4th quadrants, will appear the variables whose growth rate $(\Delta)$ is positive, that is, accelerating. The intuition is that in these quadrants will be the rates of variation positive and accelerating (1st quadrant) and negative but accelerating (4th quadrant). Similarly, in the 2nd and 3rd quadrants will be variables whose rate of change is showing deceleration (reducing the growth rate or amplifying the fall). The basic visual inspection of the monitor can be seen in Figure 3 .

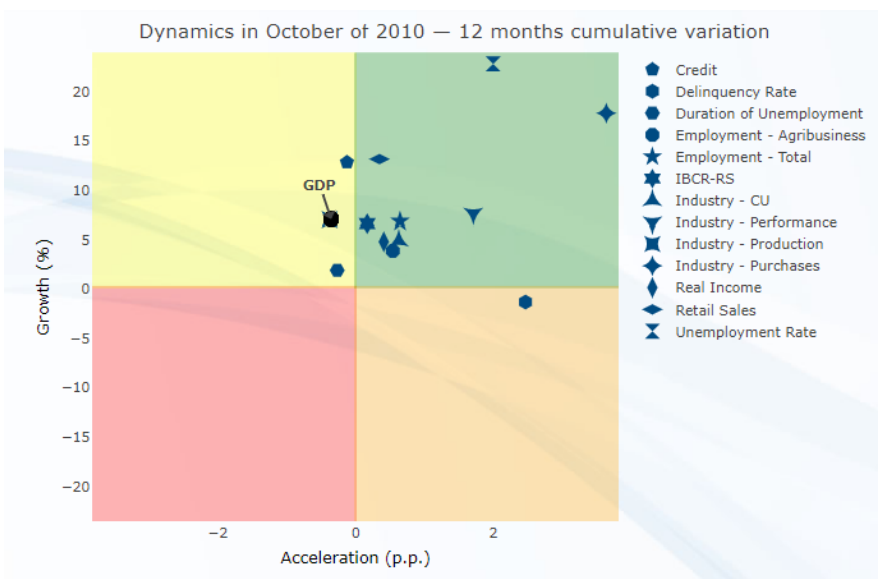

Figure 3. Picture of the macroeconomic dynamics feature of the BCT-RS - October 2010

Source: authors' elaboration.

Let us analyze a practical example in which the BCT-RS photograph helps us to understand the degree of diffusion of the movements in the selected variables of the local economy. For this, we identify two periods in which the economy of Rio Grande do Sul was expanding (continued growth in the level of activity) and two periods in which the economy was in contraction (continued decline in activity level), according to the quarterly GDP of RS (Note 18). Figure 4 identifies these periods. The idea is to show the cross-section of the rate of growth and acceleration of the system variables in these specific periods, which helps us to identify patterns.

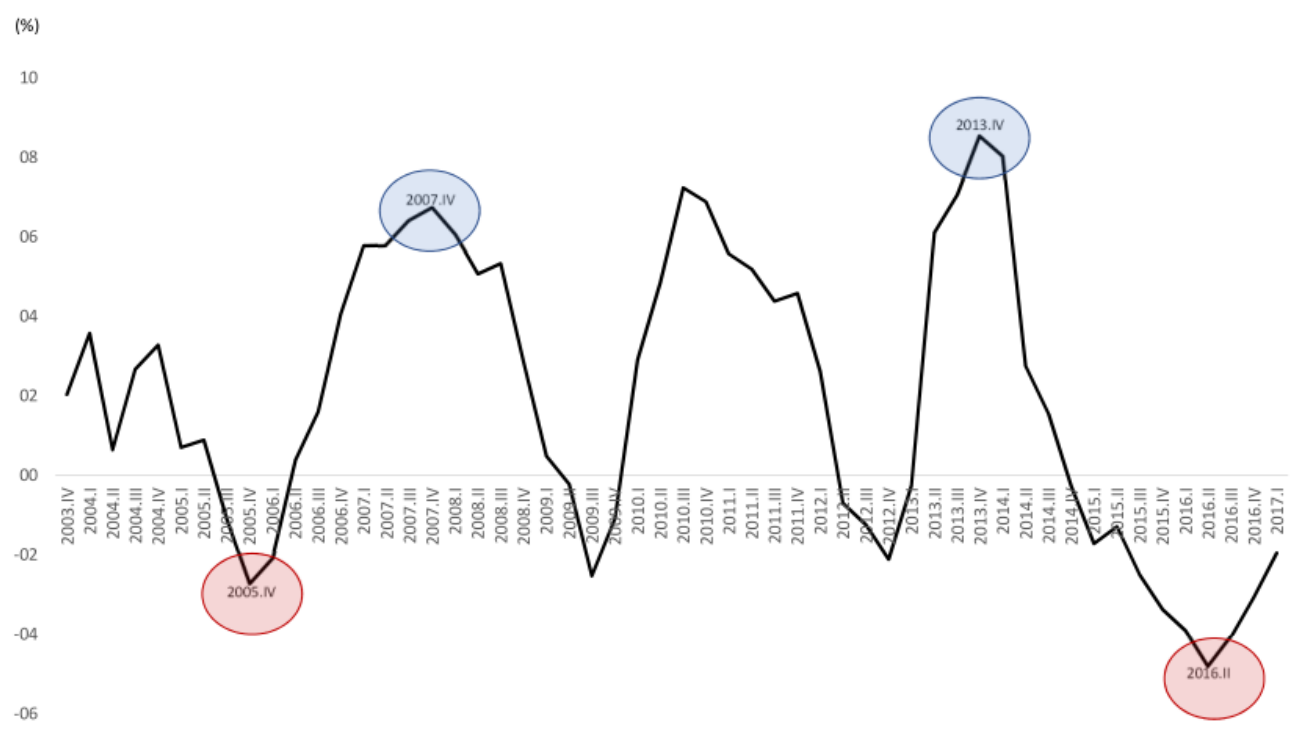

Figure 4. Identification of critical periods in the Rio Grande do Sul's GDP - 12 months cumulative growth (\%) Note. We show the cumulative twelve-month variation in the volume index of quarterly GDP of Rio Grande do Sul, from 2003 Q4 to 2017 Q1. We highlight in circles (red signals troughs, blue signals peaks) periods for which monitor variables are displayed for the purpose of interpreting the tool.

Source: authors' elaboration. 
Figure 5 shows the movements of system variables in the four periods highlighted in Figure 4: November 2005 and May 2016, that represent quarters of retraction of the economy of Rio Grande do Sul; November 2007 and November 2013, which represent periods in which the twelve-month change in GDP reaches a local maximum. It can be inferred from these four subfigures that the co-movements of the system variables are in line with those of the GDP, indicating that the system of variables, on average, coincides with the cycles of the state economic activity.

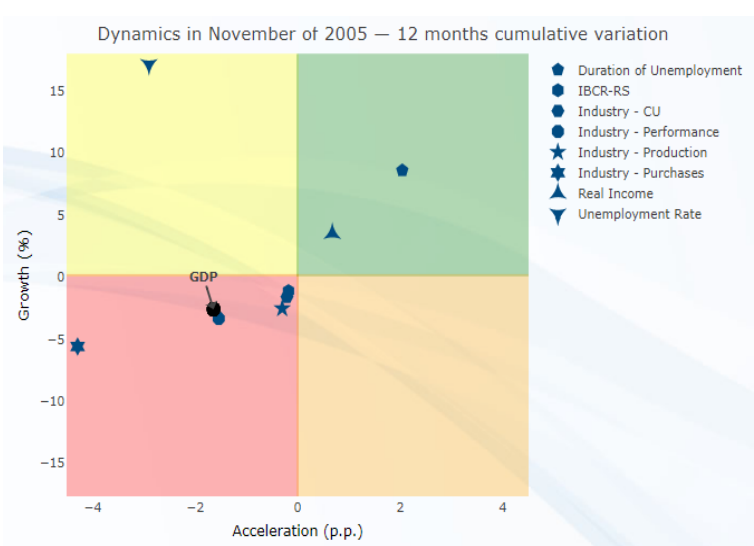

Fig. 5.a - 2005Q4 - Picture in Nov./2005

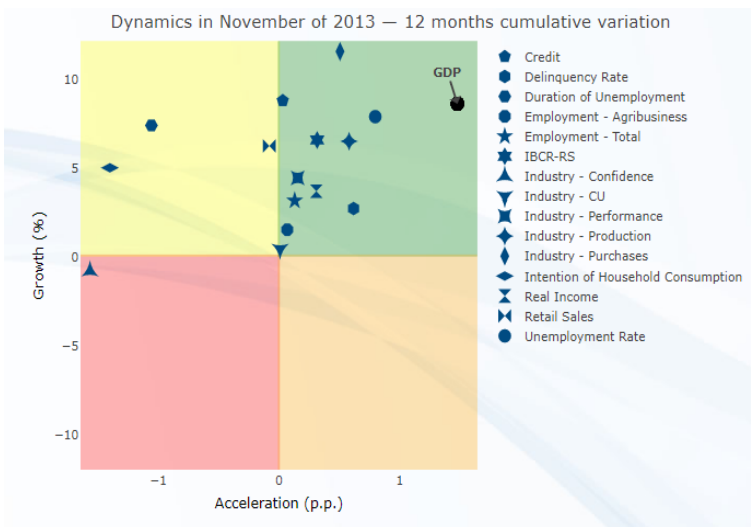

Fig. 5.c - 2013Q4 - Picture in Nov./2013

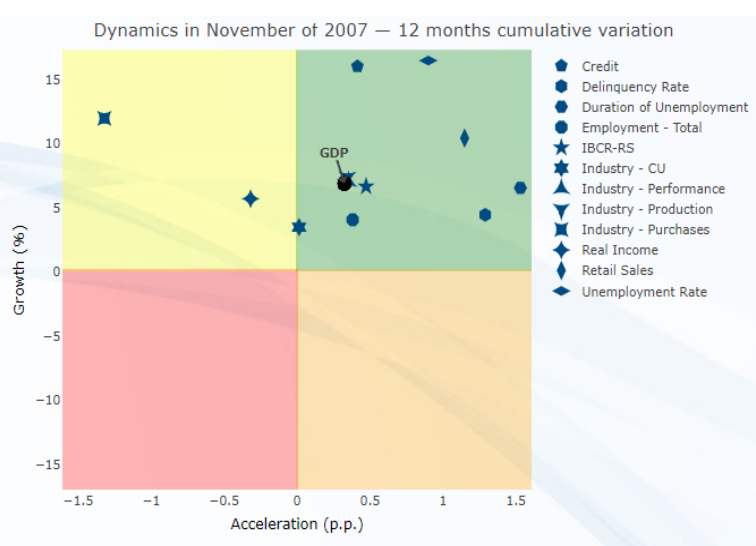

Fig 5.b - 2007Q4 - Picture in Nov./2007

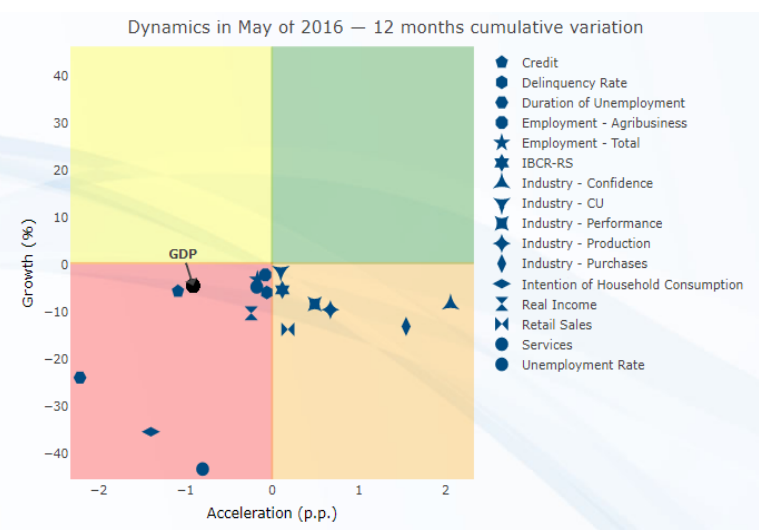

Fig 5.d - 2016Q2 - Picture in May/2016

Figure 5. Picture of the macroeconomic dynamics feature of the BCT-RS in expansion and recession periods of the local economy

Source: authors' elaboration.

Despite the similarities, there is some heterogeneity in the co-movements related to the nature and causes of cyclical phenomena, and the macroeconomic dynamics helps to identify them. For example, in the 2005-2006 recession (Figure 5.a), which had local factors causing the recession (two consecutive droughts on the RS economy), labor market variables in the metropolitan area of Porto Alegre were not declining (1st quadrant), which is consistent with the idea that the geographic regions most affected by the recession were those where there was a crop failure (ex., northwest of the state) and where agribusiness corresponds to a larger share of the economy. The metropolitan region, due to its concentration of the service sector and industrial segments not directly linked to agricultural activity, suffered less impact regarding the economic activity level.

The Figures 5.b, 5.c of November 2007 and November 2013, respectively, show how the time dynamics of the indicators were in periods of economic expansion. It is possible to observe that practically all of them indicated a good performance since they were positioned in the green quadrant (1st quadrant). Lastly, figure 5.d shows a more recent recession period of May 2016. In this chart, all indicators point to poor performance since they are either in the red quadrant (3rd quadrant) or the orange quadrant (4th quadrant), confirming the information given by the local GDP.

Hence, with the macroeconomic dynamics it is possible to monitor the evolution of relevant variables of the 
economy on a monthly basis, and in two distinct aspects: accumulated growth rate and accelerated growth rate. In addition, the user can select to graphically evaluate only variables with a given time profile: leading, coincident or lagging.

\section{Discussion and Generalization of the BCT-RS to Other Subnational Economies}

Although several economic and financial indicators are released monthly, it is still a challenge for most states to bring that scattered information in one tool. Improving data visualization is also an important development on business cycle analysis. We designed the BCT-RS to fill these gaps. The empirical tests we use to categorize variables according to their timing -- such as cross-correlation tests and the Bry-Boschan algorithm to identify recessions and expansions -- are easily done using statistical software such as Stata or R. Moreover, we show we can have an accurate view of the fluctuations on a state-level economy by monitoring five complementary dimensions of the economy: output level, labor market, sentiment indicators, credit and delinquency rate, and price indexes.

Hence, one of the advantages of our framework is that it can be easily generalized to other settings, and so we hope this paper can inspire the elaboration of tools designed to trace the business cycle fluctuations in other states and countries. We believe that both public and private agents can benefit from such applications. Tracing business cycles developments before GDP is released - usually, on a quarterly basis - provides public agents important information for policy interventions; for entrepreneurs and consumers, it helps to decide how much they should save, consume, and invest.

As a reminder, even if the theoretical aspects and the functionalities of the BCT-RS are presented and discussed in this paper, one should always consider adjustments to the economic characteristics of the state where this type of analysis is being applied. For example, as the state of Rio Grande do Sul has in its agribusiness a significant segment for both employment and household income, we gave particular attention to indicators regarding this sector. Different economic realities will give rise to different specificities in the process of selecting significant variables. Hence, one should always consider sectorial or regional specific approaches to deal with the particularities of the economy under analysis.

\section{Conclusion}

In this paper, we discuss the methodological aspects and show the core functionalities of the Business Cycle Tracer of the state of Rio Grande do Sul -- Brazil (BCT-RS). It is an innovative tool designed for monitoring the short-term fluctuations of the economy of Rio Grande do Sul (the 4th largest economy in Brazil). Importantly, our framework is generalizable to other state-level economies, especially in developing countries, where data is also limited.

Specifically, the tool focuses on the systematization of complementary indicators that, together, allow an inference not only of the current state of the economy, but also of cyclical movements in the last twenty-five years. The monthly update of all BCT-RS features provides a continuous overview of the evolution of the economy in five complementary dimensions: economic activity, labor market, sentiment indicators, credit and delinquency rate, and price indexes. We also categorize all variables according to the timing of their movements relative to the local business cycle: leading, coincident or lagging variables. Just as a physician examines a patient through multiple examinations, the BCT-RS seeks to analyze the economy from these different angles to provide the user conditions to establish an accurate diagnosis.

The BCT-RS features were designed to make the analysis simple and objective, yet robust. There are three main features: Time Series, Table of Variations and Macroeconomic Dynamics. Taken together, these functionalities seek to fill an existing gap for analysts, researchers, students, journalists from the economic area and others interested in better understanding the conjuncture of state-level economies. To gather key-economic indicators in a single tool reduces not only the time spent collecting and analyzing this information, but also improves the ability to view and interpret data. At the end of the day, it is the precise analysis of the business cycle developments that can translate into better economic decisions for people, companies, and governments.

\section{Acknowledgments}

We thank comments and suggestions from our colleagues Martinho Lazzari, Mariana Bartels, Guilherme Stein, Vanessa Sulszbach, Bruno Caldas, Juarez Meneghetti, Rafael Bernardini, Pedro Zuanazzi, Marcos Wink Jr., and Thomas Kang. We are, of course, responsible for all eventual errors.

We gratefully acknowledge the financial support for this research provided by Economics and Statistics Foundation (FEE) during the period we developed the Business Cycle Tracer of the state of Rio Grande do Sul (BCT-RS). 


\section{References}

Artis, M., Marcellino, M., \& Proietti, T. (2004). Dating business cycles: A methodological contribution with an application to the Euro area. Oxford Bulletin of Economics and Statistics, 66(4), 537-565. https://doi.org/10.1111/j.1468-0084.2004.00092.x

Braga, S. A. C. A., Fabris, M. J. Z., Guimarães, R. R. S., Schlottfeldt, C. L., \& Schneider, V. M. (2014). Indicadores de atividade econômica e boletim regional do Banco Central do Brasil: Instrumentos para análise macroeconômica regional. Retrieved from https://www.fee.rs.gov.br/wp-content/uploads/2014/05/201405237eeg-mesa2-indicadoresatividadeeconomi caboletimregionalbancocentralbrasil.pdf

Brazilian Institute of Geography and Statistics. (2017). System of Regional Accounts - Brazil - 2015. Retrieved from https://servicodados.ibge.gov.br/Download/Download.ashx?http=1\&u=biblioteca.ibge.gov.br/visualizacao/li vros/liv101307_informativo.pdf

Bry, G., \& Boschan, C. (1971). Programmed selection of cyclical turning points. In Cyclical Analysis of Time Series: Selected Procedures and Computer Programs (pp. 7-63). NBEr.

Canova, F. (1998). Detrending and business cycle facts. Journal of Monetary Economics, 41(3), $475-512$. https://doi.org/10.1016/S0304-3932(98)00008-7

Central Bank of Brazil. (2009). Regional economic activity index of Rio Grande do Sul. Regional Bulletin of the Brazilian Central Bank, 3(1), 95-97.

Central Bank of Brazil. (2012). Regional economic activity index: Revision and application of the used information. Retrieved from http://www.bcb.gov.br/pec/boletimregional/port/2012/10/br201210b3p.pdf.

Central Bank of Brazil. (2017). Time series management system. Regional Bulletin of the Brazilian Central Bank. Retrieved from https://www3.bcb.gov.br/sgspub/.

Chauvet, M. (1998). An econometric characterization of business cycle dynamics with factor structure and regime switching. International Economic Review, 969-996. https://doi.org/10.2307/2527348

Chauvet, M. (2002). The Brazilian business and growth cycles. Revista Brasileira de Economia, 56(1), 75-106. https://doi.org/10.1590/S0034-71402002000100003

Friedman, M., \& Schwartz, A. J. (1975). Money and business cycles. In The state of monetary economics (pp. 32-78). NBER.

Gyomai, G., \& Guidetti, E. (2008). OECD system of composite leading indicators. Organisation for Economic Co-Operation and Development (OECD).

Harding, D., \& Pagan, A. (2002). Dissecting the cycle: a methodological investigation. Journal of Monetary Economics, 49(2), 365-381. https://doi.org/10.1016/S0304-3932(01)00108-8

Mintz, I. (1969). Business cycles. In Dating Postwar Business Cycles: Methods and Their Application to Western Germany, 1950-67 (pp. 21-27). NBER.

National Bureau of Economic Research. (2008). The NBER's recession dating procedure. Retrieved from http://www.nber.org/cycles/jan08bcdc_memo.html

NYU Stern. (2016). Chapter 11: Business-Cycle Indicators. In The Global Economy Report, NYU Stern School of Business.

U.S. Census Bureau. (2017). X-13ARIMA-SEATS Reference Manual - Version 1.1. Center for Statistical Research and Methodology. Retrieved from https://www.census.gov/ts/x13as/docX13AS.pdf

Van Ruth, F., Schouten, B., \& Wekker, R. (2005). The statistics Netherlands business cycle tracer. Methodological aspects; concept, cycle computation and indicator selection. Statistics Netherlands, Report.

Zarnowitz, V. (1994). Business cycles: Theory, history, indicators, and forecasting. In Business Cycles: Theory, History, Indicators, and Forecasting (pp. 21-0). University of Chicago Press.

Zarnowitz, V., \& Ozyildirim, A. (2006). Time series decomposition and measurement of business cycles, trends and growth cycles. Journal of Monetary Economics, 53(7), 1717-1739. https://doi.org/10.1016/j.jmoneco.2005.03.015 


\section{Notes}

Note 1. Link: <http://visualiza.fee.tche.br/bct-rs/>, retrieved January 3, 2018.

Note 2. Most of the available economic and financial time series are short (starting in the mid-2000's). Therefore, it is a challenge to test the business cycle behavior of the series.

Note 3. Available at <https://www.cbs.nl/en-gb/visualisaties/business-cycle-tracer〉, retrieved January 2, 2018.

Note 4. Available at <https://www.newyorkfed.org/labor-conditions/index.html>, retrieved December 28, 2017.

Note 5. For more information, see <http://www.nber.org/cycles/recessions.html> (retrieved December 12, 2017).

Note 6. Note that not only the product but several other macroeconomic indicators can be decomposed this way.

Note 7. In our tests, the cyclical analysis on series in both levels and cycle component yielded similar results in most of the cases.

Note 8 . Due to the degree of rigidity observed in the labor market -- dismissing and hiring is costly -- statistical tests and economic theory suggest that the unemployment rate is lagging relative to the economic cycle.

Note 9. The Regional Accounts System, captained by the IBGE, but in sync and in conjunction with state-level research teams, announces the GDP results at current prices and constant prices for all units of the Brazilian Federation. These results, however, are always disclosed with two years of lag, representing the time to compile the information from the structural surveys (Industry, Retail Sales, Construction, Services, etc.) and others relevant to the GDP calculation (e.g., anonymous Personal Income Tax information).

Note 10. In our sample, only a few data sources provide information with seasonal adjustment. These are IBGE (Industry - Production and Services), Central Bank of Brazil (IBCR-RS), and FIERGS (Industry - Purchases, Industry - CU (1\%) and Industry - Performance). For these variables, tests of comparison and adequacy of our seasonal adjustment model were carried out -- the results are presented in Appendix A.

Note 11. A recession occurs from a peak to a trough; an expansion occurs from a trough to a peak.

Note 12. We use this criterion based on Adrian Pagan's guide available at http://www.ncer.edu.au/data/documents/BBQEXCELINSTRUCT.pdf (retrieved January 4, 2018).

Note 13. For example, the statistical tests with the unemployment rate of the metropolitan region of Porto Alegre (PED) suggested this variable is coincident (level and 1st difference) or leading (cyclic component), depending on how the variables are measured. In the literature, however, there is broad evidence that movements in unemployment rate occur in a lagged fashion to the economic cycle. Given the ambiguity of the test results, we chose to categorize the variable in a manner consistent with the literature - a lagging variable. We performed this procedure for all variables whose results were sensitive to the way in which we measured them.

Note 14. Seasonality is a term that refers to influences derived from the calendar, which are regularly repeated in the years. This achievement may result from the number of days worked in seasonal agricultural harvests, holiday workers in certain seasons, periods of the year where economic activity is higher (due to the 13th salary and year-end sales, for example), among many others factors.

Note 15. There are three countercyclical variables in the BCT-RS: unemployment rate (PED / FEE), average time to search for employment (PED / FEE) and delinquency rate (BACEN).

Note 16. Diffusion Indicators measure the proportion of variables that are varying positively in a given set of variables to the interval $[0,1]$, therefore. These indicators show the degree of spread of cyclical movements in the economy, be it between sectors, activities, segments or dimensions of the economy.

Note 17. Rudimentary, the second derivative of a function measures the variation of the rate of change itself. Thus, when $\Delta \mathrm{x}$ is small enough, the acceleration is approximated by the absolute difference in the rate of change.

Note 18. In the literature of cyclical analysis of the economy, GDP is considered the main isolated variable to measure the performance of the economy. In general, periods of expansion and recession are confirmed by the common behavior of several covariates, such as industrial production, trade sales, employment, etc. 


\section{Appendix A}

\section{Assessment of the Seasonal Adjustment Process}

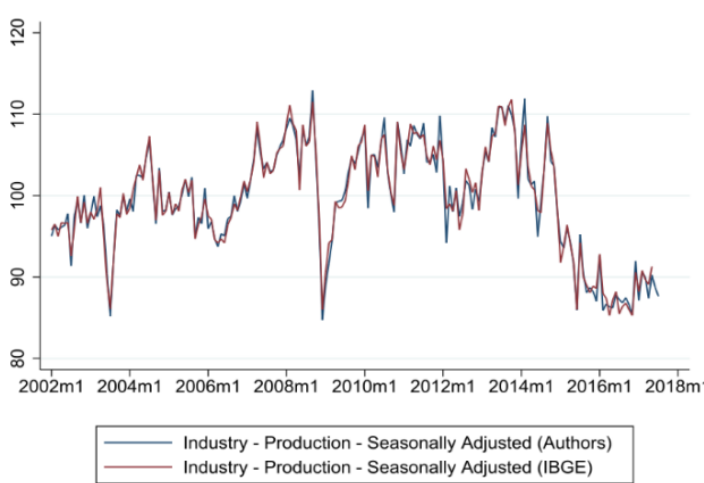

(a) Industry - Production (PIM-RS/IBGE)

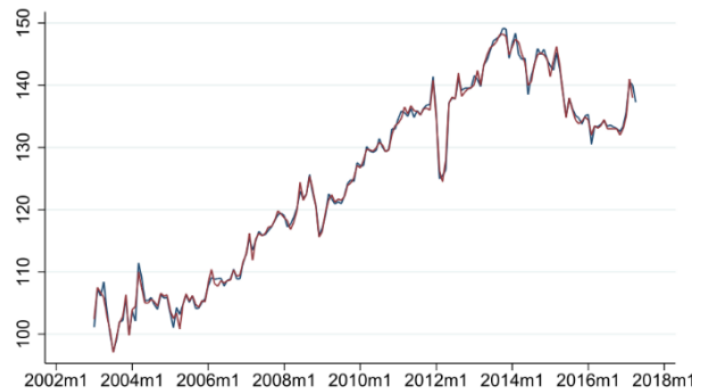

IBCR-RS - Seasonally Adjusted (Authors) IBCR-RS - Seasonally Adjusted (Central Bank of Brazil)

(c) IBCR-RS (Central Bank of Brazil)

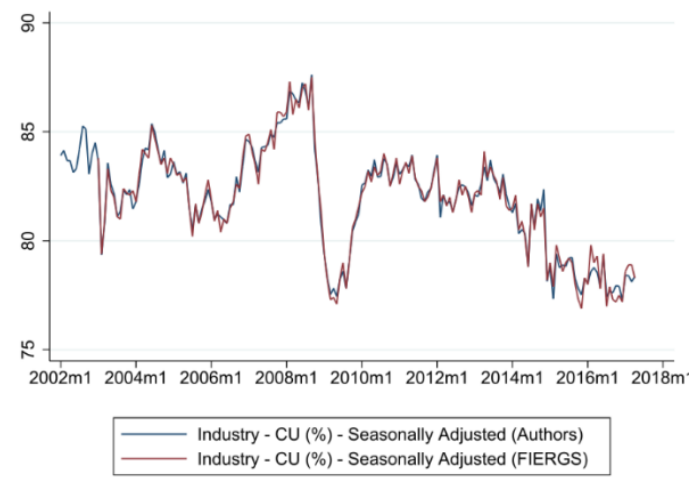

(e) Industry - CU (\%) (FIERGS)

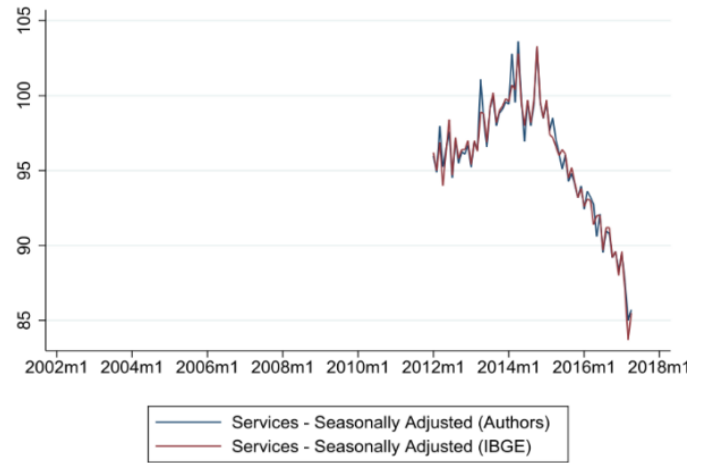

(b) Services (PMS-RS/IBGE)

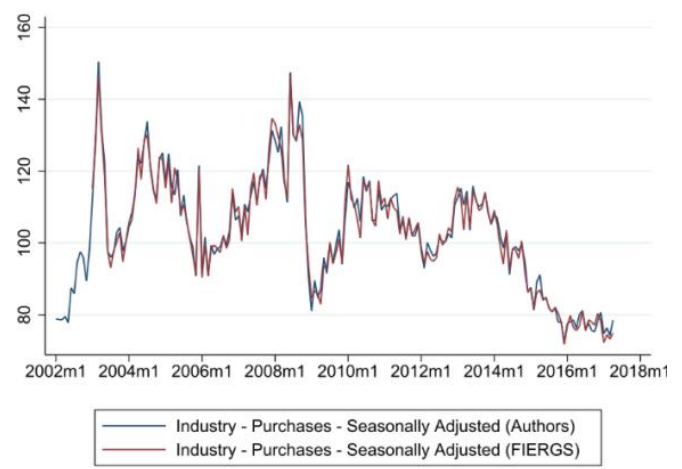

(d) Industry - Purchases (FIERGS)

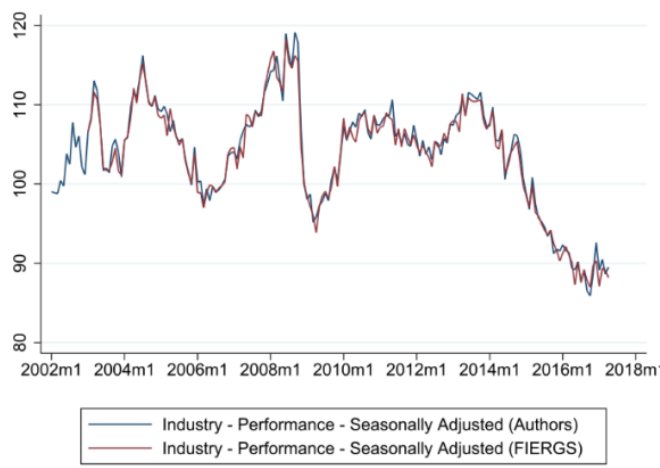

(f) Industry - Performance (IDI/FIERGS)

Figure 6. Assessment of the seasonal adjustment procedure (WinX13, U.S. Bureau) - performance against the original seasonally adjusted series

Note. The above variables are those in which the data source discloses information already seasonally adjusted. We compare the seasonally adjusted series by the entity responsible for the data (Brazilian Institute of Geography and Statistics - IBGE, Brazilian Central Bank, Federation of Industries of the State of Rio Grande do Sul - FIERGS) and our estimates, to evaluate the quality of our seasonal adjustment models. We observe from the results reported in this Figure that the series were very close to each other, suggesting an excellent performance of our seasonal adjustment process. Therefore, we include in the BCT-RS our seasonally adjusted estimates for the series in which the data source does not provide seasonally adjusted information.

Source: authors' elaboration.

\section{Copyrights}

Copyright for this article is retained by the author(s), with first publication rights granted to the journal.

This is an open-access article distributed under the terms and conditions of the Creative Commons Attribution license (http://creativecommons.org/licenses/by/4.0/). 